\title{
Saturated-Subcooled Stratified Flow in Horizontal Pipes
}

\section{FEDSM-ICNMM 2010}

\author{
Richard R. Schultz \\ Hiral J. Kadakia \\ Jim C. P. Liou \\ Brian G. Williams
}

The INL is a

U.S. Department of Energy

National Laboratory

operated by

Battelle Energy Alliance

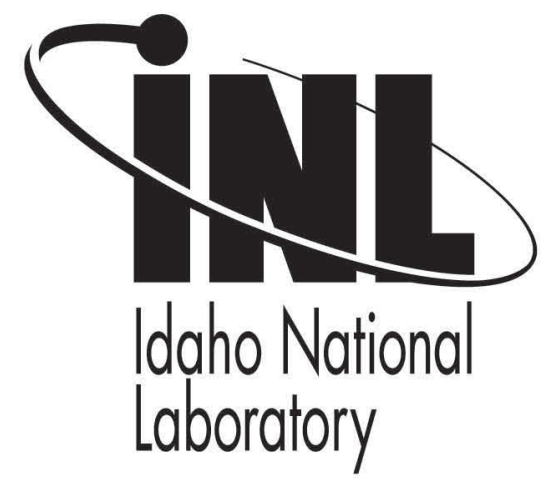

\section{August 2010}

This is a preprint of a paper intended for publication in a journal or proceedings. Since changes may be made before publication, this preprint should not be cited or reproduced without permission of the author. This document was prepared as an account of work sponsored by an agency of the United States Government. Neither the United States Government nor any agency thereof, or any of their employees, makes any warranty, expressed or implied, or assumes any legal liability or responsibility for any third party's use, or the results of such use, of any information, apparatus, product or process disclosed in this report, or represents that its use by such third party would not infringe privately owned rights. The views expressed in this paper are not necessarily those of the United States Government or the sponsoring agency. 


\section{FEDSM-ICNMM2010-30975}

\section{SATURATED-SUBCOOLED STRATIFIED FLOW IN HORIZONTAL PIPES}

\author{
Richard R. Schultz \\ Idaho National Laboratory \\ Idaho Falls, Idaho 83415 USA \\ Jim C. P. Liou \\ University of Idaho \\ Moscow, Idaho 83844 USA
}

\author{
Hiral J. Kadakia \\ Idaho State University \\ Pocatello, Idaho 83209 USA \\ Brian G. Williams \\ Idaho State University \\ Pocatello, Idaho 83209 USA
}

\begin{abstract}
Advanced light water reactor systems are designed to use passive emergency core cooling systems with horizontal pipes that provide highly subcooled water from water storage tanks or passive heat exchangers to the reactor vessel core under accident conditions. Because passive systems are driven by density gradients, the horizontal pipes often do not flow full and thus have a free surface that is exposed to saturated steam and stratified flow is present.
\end{abstract}

The subcooled water flows into the reactor vessel via the downcomer-which is an annular region separated from the core by a cylindrical, steel, inner liner. Under accident conditions, where the horizontal pipes are only partially full, both saturated water and saturated steam from the downcomer are likely to be present in the pipe. The saturated water is quasi-static and the fraction of the free surface that is saturated water is dictated by the physics of the flow. The saturated steam is usually flowing in the countercurrent direction to the subcooled water. Consequently the flow may be a three-layered system with saturated steam over a static saturated liquid layer over a flowing subcooled layer.

The conditions leading to a saturated liquid layer that separates the saturated steam from flowing subcooled water are explored. The variables that influence the formation of the saturated liquid layer and enable the saturated layer to be maintained for a spectrum of conditions, including steam flow in the countercurrent direction to the subcooled water, are derived, and compared to experimental data. Conclusions regarding this type of flow are given. Finally, typical steam flow velocities that may induce wave-bridging, leading to condensation-induced-water hammer, are identified.

\section{NOMENCLATURE}

$\mathrm{A}_{1}=$ Flow area of lighter liquid $\left(\mathrm{m}^{2}\right)$

$\mathrm{A}_{2}=$ Flow area of heavier liquid $\left(\mathrm{m}^{2}\right)$

$A_{\text {gas }}=$ Flow area of gas $\left(\mathrm{m}^{2}\right)$

$\mathrm{D}=$ Pipe diameter $(\mathrm{m})$

$\mathrm{f}=$ Friction factor

$\mathrm{F}_{1}=$ Force on lighter liquid control volume (n)

$\mathrm{F}_{2}=$ Force on heavier liquid control volume (n)

$\mathrm{g}=$ Gravitational acceleration

$\mathrm{h}_{1}=$ Thickness of wedge $(\mathrm{m})$

$\mathrm{h}_{2}=$ Depth of heavier flow liquid (m)

$\mathrm{M}_{2}=$ Momentum flux of heavier liquid (n)

$\mathrm{Q}=$ liquid flow rate $\left(\mathrm{m}^{3} / \mathrm{s}\right)$

$\mathrm{R}=$ Pipe radius $(\mathrm{m})$

$\operatorname{Re}=$ Reynolds number

$\mathrm{S}_{\mathrm{I}}=$ Steam-liquid interface perimeter at cross-section (m) 
$\mathrm{S}_{\mathrm{L}}=$ Liquid-wall interface perimeter at cross-section (m)

$\mathrm{S}_{\mathrm{b}}=$ Friction force/length at pipe boundary $(\mathrm{n} / \mathrm{m})$

$\mathrm{S}_{\mathrm{i}}=$ Interfacial shear force at liquid-liquid interface $(\mathrm{n} / \mathrm{m})$

$\mathrm{S}_{\mathrm{s}}=$ Interfacial shear force at gas-liquid interface $(\mathrm{n} / \mathrm{m})$

$\mathrm{V}_{2}=$ Velocity of heavier liquid $(\mathrm{m} / \mathrm{s})$

$\mathrm{V}_{\text {gas }}=$ Velocity of gas $(\mathrm{m} / \mathrm{s})$

$\mathrm{x}=$ Distance along axis of pipe $(\mathrm{m})$

$\alpha=$ Angle of pipe radius to normal where interface between lighter and heavier liquid intersects with pipe wall

$\alpha_{0}=$ Angle of pipe radius to normal where interface of free surface intersects with pipe wall

$\bar{\alpha}=$ void fraction

$\hat{\alpha}=$ void fraction at cusp of wave

$\Delta \mathrm{E}_{\mathrm{i}}=$ Energy change

$\Delta \mathrm{P}_{\mathrm{i}}=$ Net force per unit area for contribution $\mathrm{i}\left(\mathrm{n} / \mathrm{m}^{2}\right)$

$\gamma_{1}=$ Specific weight of lighter liquid $\left(\mathrm{n} / \mathrm{m}^{3}\right)$

$\gamma_{2}=$ Specific weight of heavier liquid $\left(\mathrm{n} / \mathrm{m}^{3}\right)$

$v=$ Kinematic viscosity $(\mathrm{n}-\mathrm{m} / \mathrm{s})$

$\rho_{1}=$ Density of lighter liquid $\left(\mathrm{kg} / \mathrm{m}^{3}\right)$

$\rho_{2}=$ Density of heavier liquid $\left(\mathrm{kg} / \mathrm{m}^{3}\right)$

$\rho_{\text {gas }}=$ Density of gas $\left(\mathrm{kg} / \mathrm{m}^{3}\right)$

$\tau_{\mathrm{b}}=$ Shear force at boundary $\left(\mathrm{n} / \mathrm{m}^{2}\right)$

\section{INTRODUCTION}

Experiments performed to study the behavior of passive emergency core cooling systems (ECCS) in advanced light water reactors have demonstrated that some modes of operation may result in conditions where horizontal pipes have saturated steam that flows over a layer of quasi-static saturated water which separates flowing subcooled water from the steam volume. Examples of this behavior, recorded in experiments, (Schultz et al. 2001; Yonomoto et al 1997; and Yonomoto et al. 2001) occur in horizontal piping that is plumbed to the reactor vessel downcomer. The source of subcooled water is a passive ECCS designed to deliver subcooled water to the core region via the reactor vessel downcomer. The source of steam is the reactor vessel steam space over the downcomer water level. Hence the steam flows in the countercurrent direction to the subcooled water. The layer of static saturated water originates from the downcomer and may extend over the length of the horizontal pipe or over only a fraction of the horizontal pipe. The geometry of this condition is shown in Figure 1.

To investigate the mechanics of the above flow condition, experiments have been accomplished to study: (a) the variables that govern the penetration of the saturated layer from the downcomer into the horizontal pipe and (b) the effect of the steam flow on the saturated layer for 2 conditions: the extent to which the steam "drags" the layer into the pipe and the steam flow rates that may result in "wave-bridging" that leads to condensation-induced water hammer. These effects are described in the following sections. The work described herein is documented in more detail in Schultz, 2010.

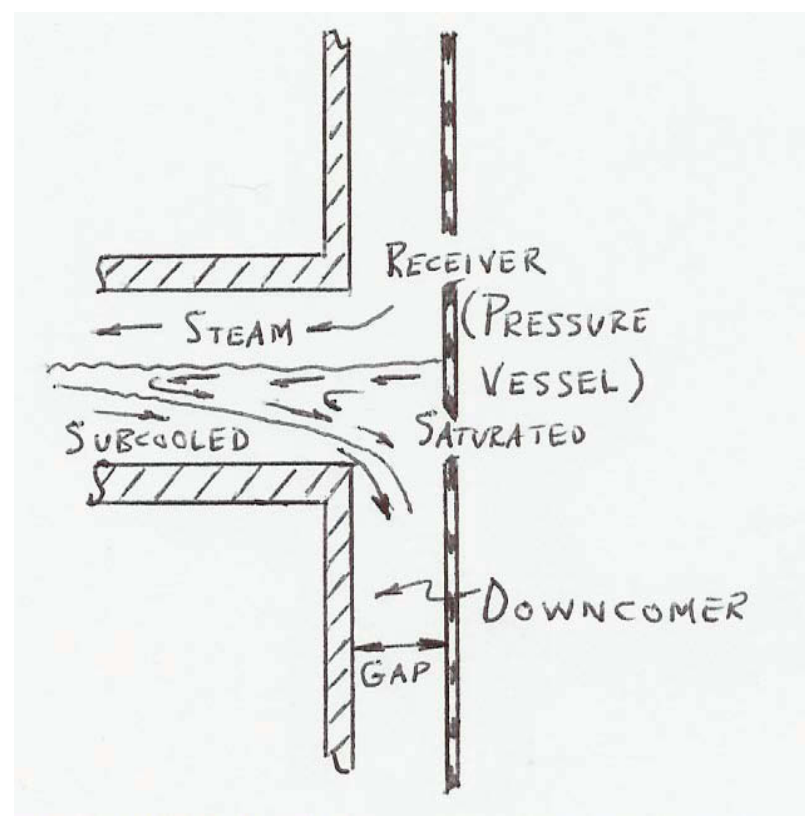

Figure 1. Stratified flow in a horizontal pipe; subcooled water flowing into receiver with steam flowing into the pipe from receiver; saturated liquid wedge separating steam and subcooled layer.

\section{LOCATION OF THE STRATIFIED LIQUID LAYER}

Earlier research, performed to study the formation of a liquid layer and its behavior in the presence of a heavier layer of flowing liquid, was reported in Liou et al 2005. The layer of lighter liquid is commonly termed a "wedge" in the literature. The research reported in the Liou et al 2005 reference used brine for the heavier fluid and subcooled water for the lighter fluid. Using the nomenclature shown in Figure 2, the following equations are relevant.

Using the angles $\alpha_{\mathrm{o}}$ and $\alpha$ (see Figure 2) the thickness of the stratified wedge and the depth of the flowing subcooled water may be described as $h_{1}$ and $h_{2}$ respectively:

$$
\begin{aligned}
& h_{1}=R\left(\cos \alpha_{o}-\cos \alpha\right) \\
& \left.h_{2}=R(1+\cos \alpha)\right)
\end{aligned}
$$

where $h_{1}$ and $h_{2}$ are also shown in Figure 2.

Using equations (1) and (2) the flow areas of the saturated wedge and the subcooled water flow are expressed respectively as:

$$
A_{1}=R^{2}\left[\frac{\sin 2 \alpha_{o}}{2}-\frac{\sin \alpha}{2}-\left(\alpha_{o}-\alpha\right)\right]
$$


(4) $A_{2}=R^{2}\left(\pi-\alpha+\frac{\sin \alpha}{2}\right)$

At any flow cross-section, the forces $F_{1}$ and $F_{2}$ may be derived by assuming a hydrostatic force balance is present in the vertical direction for an element and by integrating. Also it is assumed there is no mixing. Thus for $\mathrm{F}_{1}$ :

(5) $F_{1}=2 \gamma_{1} R^{3}\left\{\cos \alpha_{o}\left[\alpha-\alpha_{o}-\frac{\sin 2 \alpha-\sin \alpha_{o}}{2}\right]-\right.$

$$
\frac{2}{3}\left[(\sin \alpha)^{3}-\left(\sin \alpha_{o}\right)^{3}\right\}
$$

And for $\mathrm{F}_{2}$ :

(6) $F_{2}=R^{3} \gamma_{2}\left\{\begin{array}{l}{\left[\frac{\gamma_{1}}{\gamma_{2}}\left(\cos \alpha_{0}-\cos \alpha\right)+\cos \alpha\right]} \\ {\left[\pi-\alpha+\frac{\sin 2 \alpha}{2}\right]+\frac{2}{3}(\sin \alpha)^{3}}\end{array}\right\}$ where $\gamma_{1}$ and $\gamma_{2}$ are the specific weights of the lighter and heavier fluids respectively.

It is assumed that the wedge, identified as fluid 1 in the control volume diagram shown in Figure 2, is stationary. Consequently the momentum flux is zero for fluid 1 . The momentum flux in the $\mathrm{x}$-direction for fluid 2 is:

$$
M_{2}=\frac{\rho_{2} Q^{2}}{A_{2}}
$$

The other forces indicated in Figure 2 are the interfacial shear force at the liquid free surface that is a function of the gas flow rate: $S_{s}$, the interfacial shear force between the stationary wedge and the flowing subcooled water: $\mathrm{S}_{\mathrm{i}}$, and the shear force exerted by the wall on the flowing liquid: $\mathrm{S}_{\mathrm{b}}$.

The interfacial shear force at the liquid free surface may be approximated using the work done by Blasius 1908 to characterize the drag on flat plates as noted in Schlichting 1960:

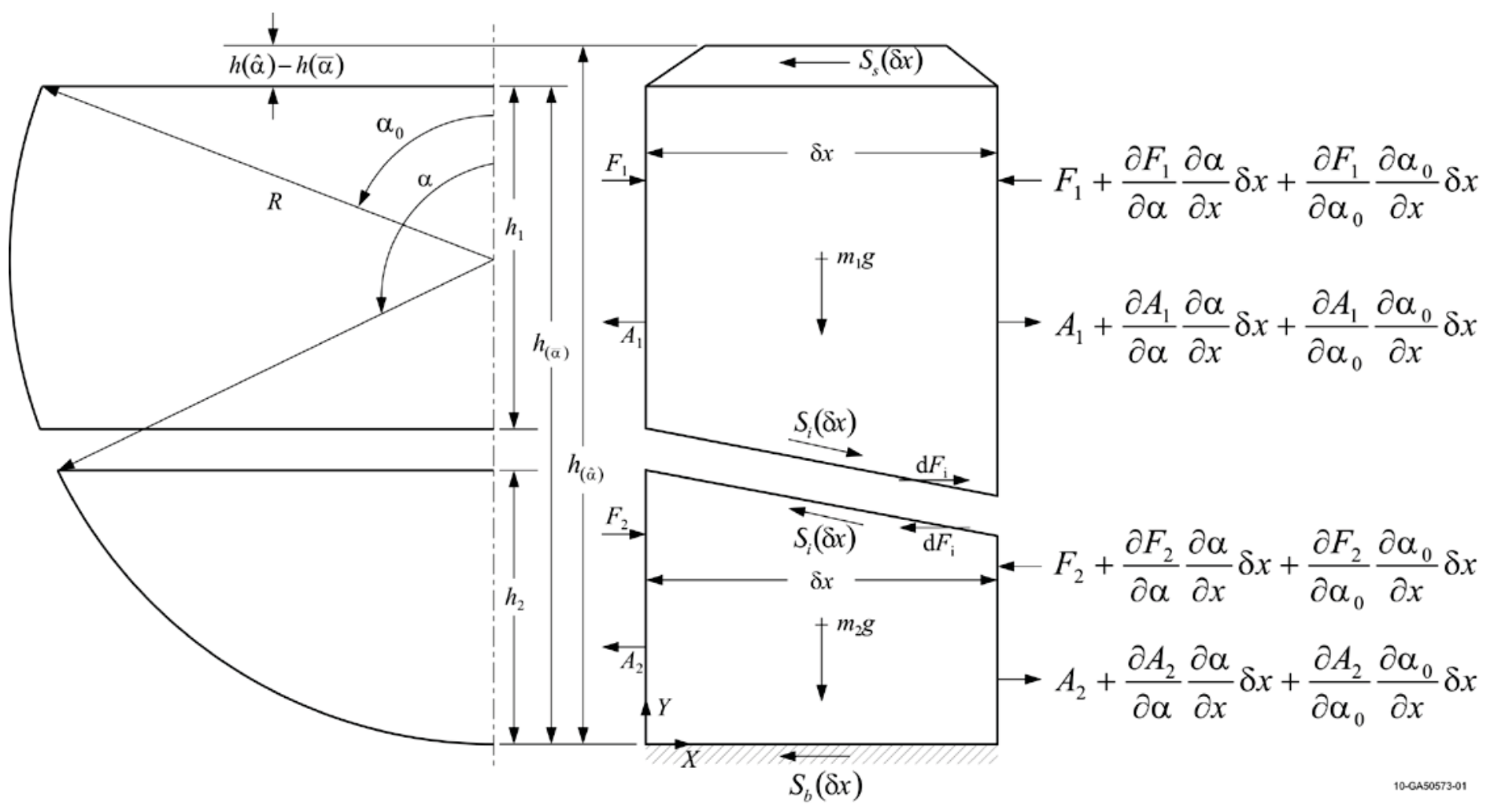

a. End view—showing pipe radius and interface location b. Side view-showing (i) angle between lighter fluid and heavier fluid and (ii) wave height.

Figure 2. Nomenclature 
(8) $S_{s}=\frac{0.664}{\sqrt{\mathrm{Re}_{\text {xgas }}}} \rho_{\text {gas }} \frac{V_{\text {gas }}^{2}}{2}\left(2 R \sin \alpha_{o}\right)$

where the Reynolds number is:

$$
R e_{x g a s}=\frac{x_{g a s} V_{g a s}}{v_{g a s}}
$$

where $V_{\text {gas }}$ is the velocity of the gas flow and $v_{\text {gas }}=$ the gas kinematic viscosity and the flow and state properties are for the flowing gas, whether it is steam, air, or otherwise, and the distance $x_{\text {gas }}$ is measured from the plane where the horizontal pipe is plumbed into the receiver vessel and is measured in the upstream direction.

The interfacial shear force between the stationary wedge and the flowing subcooled water: $\mathrm{S}_{\mathrm{i}}$ was used in Liou et al 2005 based on the Bo Petersen 1986 adaptation of the Balsius approximation where the relationship is expressed in terms of the distance $\mathrm{x}$ from the leading edge of the stationary wedge in the downstream direction of the flow:

$$
S_{i}=\frac{0.664}{\sqrt{\mathrm{Re}_{x}}} \rho_{2} \frac{V_{2}^{2}}{2}(2 R \sin \alpha)
$$

where

$$
R e_{x 2}=\frac{x_{2} V_{2}}{v_{2}}
$$

and $V_{2}=$ the velocity of the subcooled liquid and $v_{2}=$ the subcooled liquid kinematic viscosity.

Finally, the shear force exerted by the wall on the flowing liquid: $S_{b}$ is expressed by equation (12):

$$
S_{b}=\frac{\rho_{2} f}{8}\left(\frac{Q}{A}\right)^{2}[2(\pi-\alpha) R]
$$

where $f=$ the Darcy-Weisbach friction factor which is evaluated using the Reynolds number based on the hydraulic radius of the subcooled liquid flow. It should be noted that for all the experiments performed to date, the region of interest is for laminar flow-and for this condition, friction factor equals $64 / \operatorname{Re}$ where $\mathrm{Re}=$ the appropriate Reynolds number.

Using the force balance and $\mathrm{x}$-direction momentum, as expressed in Figure 2 across the control volume for region 2:

$$
\frac{\partial}{\partial \alpha}\left(F_{1}+F_{2}+M\right) \frac{d \alpha}{d x}=-S_{b}-S_{i}(1-\Phi)-S_{s} \Phi
$$

where $\Phi=\frac{\pi-\alpha+\frac{\sin 2 \alpha}{2}}{\alpha_{0}-\alpha-\frac{\sin 2 \alpha_{0}-\sin 2 \alpha}{2}}$

The derivatives on the left-hand side of equation (13) are:

$$
\frac{\partial F_{1}}{\partial \alpha}=2 \gamma_{1} R^{3}(\sin \alpha)^{2}\left[\cos \alpha_{O}-\cos \alpha\right]
$$

$$
\begin{gathered}
\frac{\partial F_{2}}{\partial \alpha}=-R^{3}\left\{\left[\gamma_{2}-\gamma_{1}\right]\left[\pi-\alpha+\frac{\sin 2 \alpha}{2}\right]+\right. \\
\left.\left[2 \gamma_{1} \sin \alpha\right]\left[\cos \alpha_{o}-\cos \alpha\right]\right\}
\end{gathered}
$$

$$
\frac{d M}{d \alpha}=\frac{2 \rho_{2} Q^{2} R^{2}(\sin \alpha)^{2}}{\left[R^{2}\left(\pi-\alpha+\frac{\sin 2 \alpha}{2}\right]\right.}
$$

From equation (13) the total length of the stationary wedge may be calculated, as described in Liou et al 2005 by integrating from the leading edge with a lower integration limit of $\alpha_{0}{ }^{*}$ (which is the value of $\alpha$ at the leading edge of the wedge) to $\alpha$ at the opposite end of the wedge. The integral is a function of both $\alpha$ and $\alpha_{0}$. However the data have shown that although $\alpha_{0}$ decreases in the direction of the subcooled liquid flow, the change in $\alpha_{o}$ may be neglected for a first approximation. The integral is given in Equation (17) as:

$$
x=-\int_{\alpha_{o}^{*}}^{\alpha}\left\{\frac{\frac{\partial}{\partial \boldsymbol{\alpha}}\left(F_{1}+F_{2}+M\right)}{\left[S_{b}+S_{i}(1-\Phi)+S_{S} \Phi\right]}\right\} d \boldsymbol{\alpha}
$$

As noted in Liou et al 2005, the denominator of the integrand is always positive such that for a wedge to exist the numerator must be negative. 
It is interesting to note that equation (13) devolves to the equation for gradually-varied flow in a circular cross-section pipe that has been used by other researchers (Bjorge 1983; Bjorge and Griffith 1984; Henderson 1966):

$$
\left[1-\mathrm{FrNo}^{2}\right]=\frac{d h_{2}^{*}}{d x^{*}}=-\tau^{*}
$$

where

$$
\tau^{*}=\frac{S_{L}}{\rho_{2} g A_{2}} \tau_{b}
$$

$$
x^{*}=\frac{x}{D}
$$

for no gas flow and with no stratified wedge present.

\section{INFLUENCE OF GAS FLOW ON WEDGE}

The presence of gas flow, moving from the receiver (the pressure vessel) toward the upstream end of the pipe will "drag" the wedge toward the upstream end of the pipe. The influence of the gas is represented in equation (13) by the rightmost term. As the gas flow rate increases, the drag-force on the wedge increases. But ultimately larger gas velocities lead to the possibility of wave bridging and transition from horizontally-stratified flow to slug flow in the pipe. This limit must be carefully considered.

At the junction of the horizontal pipe to the pressure vessel (sometimes called receiver) - see Figure 1: as the steam or air moves into the horizontal pipe from the receiver, it accelerates. The flow contracts for a distance equal to approximately 0.4 hydraulic diameters and then the flow expands and fills the pipe gas flow area for approximately another 0.4 hydraulic diameters (Idel'chek 1960). The contraction followed by expansion forms a vena contracta that is characterized by first an increasing velocity as the flow contracts followed by a decreasing velocity as the flow expands. In accelerating flow is accompanied by a decrease in the static pressure and the expanding flow is accompanied by an increase in the static pressure.

For a constant area horizontal pipe that is partially-filled with liquid, the pipe cross-section with the highest gas velocity is approximately 0.4 hydraulic diameter upstream of the pipe/pressure vessel junction. Thus at this location the lowest static pressure is developed. Dependent on the entrance geometry, the effective flow area at the location of highest velocity may be reduced by $20 \%$ or more of the available flow area (typical values are 0.8 ). Consequently wave bridging, induced by this effect is most likely to occur in this region. For steam flow, with condensation in the pipe section, the highest velocity flows will most likely be measured at the entrance not only because of the presence of the vena contracta, but also because the steam velocity will decrease as steam condenses along the pipe length. Hence study of the wave bridging phenomena was focused at the pipe/pressure vessel juncture (see Figure 1) for many of the experiments described in subsequent sections. And indeed, experiments performed to study wave-bridging for this problem found that all wave bridging occurred near the pipe to vessel junction as expected. These data will be discussed in the subsequent section.

To study the lift forces that will occur as waves are formed it is convenient to use the form of equation (4) to define the gas void fraction:

$$
\bar{\alpha}=\frac{A_{\text {gas }}}{A_{\text {Total }}}=1-\frac{A_{\text {liquid }}}{A_{\text {Total }}}
$$

where

$$
A_{\text {Liquid }}=R^{2}\left(\pi-\alpha_{o}+\frac{\sin \alpha_{o}}{2}\right)
$$

such that

$$
\bar{\alpha}=\frac{1}{\pi}\left[\alpha_{o}-\sin \alpha_{o} \cos \alpha_{o}\right]
$$

and

$$
\bar{\alpha}=\frac{1}{\pi}\left[\cos ^{-1} \Psi-\Psi\left[1-\Psi^{2}\right]^{1 / 2}\right]
$$

where $\quad \Psi=\frac{2 h(\bar{\alpha})}{D}-1 \quad$ and $\quad h_{(\bar{\alpha})}=h_{1}+h_{2}$ is the undisturbed liquid level—as shown in Figure 2.

When a wave is formed the liquid level at the wave cusp is defined $h_{(\hat{\alpha})}$ (see Figure 2) such that:

$$
\hat{\Psi}=\frac{2 h(\hat{\alpha})}{D}-1 \text { and }
$$




$$
\hat{\alpha}=\frac{1}{\pi}\left[\cos ^{-1} \hat{\Psi}-\hat{\Psi}\left[1-\hat{\Psi}^{2}\right]^{1 / 2}\right]
$$

where $h_{(\widehat{\alpha})}=h_{(\bar{\alpha})}+\delta h$ and $\delta h$ is the wave height.

Using equations (26) and (27) the net lift force per unit area for any given wave can be defined as:

$$
\Delta \mathrm{P}_{l i f t}=\Delta P_{k p}+\Delta P_{g a s}-\Delta P_{G}
$$

where $\Delta P_{k p}$ is the lift attributed to the flowing liquid stemming from the increased flow area as conversion from kinetic to potential energy occurs, $\Delta P_{\text {gas }}$ is the lift stemming from the Bernoulli effect at the wave cusp, and $\Delta P_{G}$ is the net hydrostatic force exerted by the net mass of the wave and its displacement of the gas above it. Each of these components is briefly defined in a manner consistent with the approach used by Minato et al 1986.

\section{Conversion of Kinetic to Potential Energy of Subcooled Water}

Flow: The $\Delta P_{k p}$ term, as first derived by Minato et al 1986, results from the change (increase) in the fraction of the liquid at the plane of the wave as expressed by:

$$
\Delta E_{k p}=\frac{1}{2} \rho_{\text {liquid }} V_{2}^{2}\left[1-\left(\frac{1-\bar{\alpha}_{2}}{1-\widehat{\alpha}_{2}}\right)^{2}\right]
$$

where equation (29) gives the energy change on a unit cell basis and the subscript 2 on the $\bar{\alpha}_{2}$ and $\hat{\alpha}_{2}$ terms denotes the change in liquid fraction resulting from the flowing liquid level only. Consequently, the total energy change for the total fluid volume is:

$$
\begin{aligned}
\Delta E_{\text {total }}=\left(1-\bar{\alpha}_{2}\right) \Delta E_{k p}= \\
\\
\qquad \int_{0}^{\Delta V o l} \Delta P_{k p} d V o l=\Delta P_{k p} \Delta \text { Vol }
\end{aligned}
$$

where since:

$$
\Delta V o l=\frac{\bar{\alpha}_{2}-\widehat{\alpha}_{2}}{1-\widehat{\alpha}_{2}}
$$

is the fraction of the wave height that can be attributed to the change from the kinetic to potential energy of the liquid stream then:

$$
\Delta P_{k p}=\frac{\Delta E_{k p}}{\Delta \mathrm{Vol}}=\frac{1-\widehat{\alpha}_{2}}{\bar{\alpha}_{2}-\widehat{\alpha}_{2}}\left(1-\bar{\alpha}_{2}\right) \Delta E_{\text {total }}^{k p}=
$$

$$
\frac{1}{2} \rho_{\text {liquid }} V_{2}^{2} \frac{\left(1-\bar{\alpha}_{2}\right)\left(2-\bar{\alpha}_{2}-\widehat{\alpha}_{2}\right)}{1-\widehat{\alpha}_{2}}
$$

Bernoulli-Effect Stemming from Gas Flow: Changes in the gas velocity stemming from wave formation and the resultant decrease in gas flow area are expressed as:

$$
\Delta P_{\text {gas }}=\frac{1}{2} \rho_{\text {gas }} V_{\text {gas }}^{2}\left[\left(\frac{\bar{\alpha}}{\widehat{\alpha}}\right)^{2}-1\right]
$$

where the gas velocity is that at the minimum area of the vena contracta encountered approximately 0.4 hydraulic diameter into the pipe from the pipe juncture to the pressure vessel— see Figure 1.

Hydrostatic-Effect of Wave Liquid-Gas Interchange: The mass of the liquid that forms the net change in height of the free surface (the wave height above the free surface), considering the gas volume that is replaced by the liquid mass, exerts a downward force at the plane of interest that may be expressed in terms of a negative lift as follows:

$$
\begin{array}{r}
\Delta P_{G}=\left(\gamma_{1}-\gamma_{g a s}\right)\left(h_{(\widehat{\alpha})}-h_{(\bar{\alpha})}\right)+ \\
\left(\gamma_{2}-\gamma_{1}\right)\left(h_{(\widehat{\alpha})_{2}}-h_{(\bar{\alpha})_{2}}\right)
\end{array}
$$

where the right-most term is often neglected.

Minato et al 1986 used the above approach to calculate the transition from horizontally-stratified flow to slug-flow for an air-water system and compared their calculational results both to their data and to the theory developed by Taital and Dukler 1976. Their calculations compared closely to both.

Minato et al 1986 performed their comparisons for air flowing in the co-current direction with water with no intermediate stratified layers. Thus the pipe was fully occupied with flowing fluid and consequently it was appropriate to use a figures-of-merit based on liquid and gas superficial velocitiesas is usual for such systems. For the present effort, because of the presence of a nonflowing liquid wedge, it does not seem appropriate to perform comparisons using superficial fluid velocities and instead absolute velocity ranges will be used in the subsequent data comparisons.

\section{SUMMARY OF EXPERIMENTAL EFFORT}

To further study the theory developed above, two experimental systems were designed and used: (i) an air-water apparatus and (ii) a steam-water loop. Each of these systems will be briefly described and then the data obtained in each will be summarized prior to comparing the theory with the experimental data. 
Air-Water Apparatus: This hardware was constructed of Lexan and consisted of a $1.02 \mathrm{~m}$ long $0.0444 \mathrm{~m}$ diameter horizontal pipe section plumbed into a $0.300 \mathrm{~m}$ diameter verticallyoriented cylindrical pipe section that served as a reservoir. Room temperature water was provided at the upstream end of the horizontal pipe section and the water flow rate was measured using a calibrated turbine meter. The water moved along the horizontal pipe section and flowed into the reservoir where it was allowed to drain at a prescribed rate such that a constant reservoir water level was maintained according to the test objectives.

An air feed line was plumbed to the top of the reservoir section and the air flow rate was measured using a critical orifice. The air was directed into the horizontal pipe section where it flowed in the counter-current direction to the water. The air was allowed to vent to atmosphere at the upstream end of the test section.

Some experiments were performed with only air and water to calibrate the experiment. These experiments were followed by tests using water as the heavier fluid and canola oil as the lighter fluid. Since canola oil is immisible, mixing between the two liquids was minimal. Most of the experiments were performed using water as the heavier fluid and a miscible grape-colored alcoholic fluid at specific gravities that ranged from $96 \%$ to $99 \%$ of that of water. Figure 3 shows the air-water apparatus.

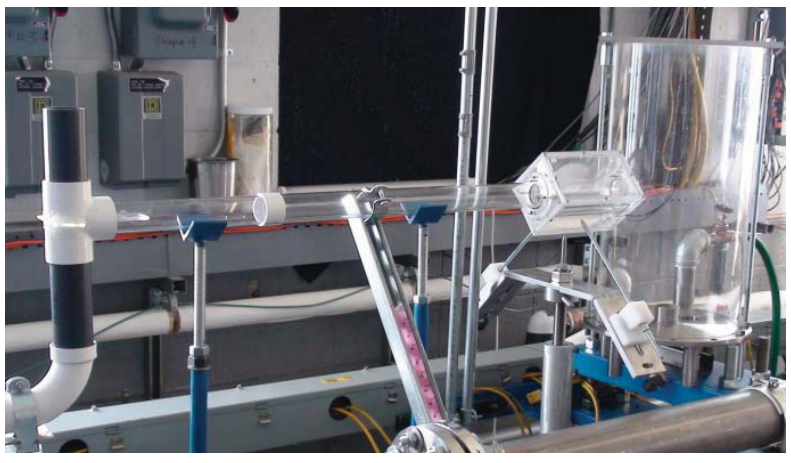

Figure 3. Air-Water Apparatus: Feedwater enters horizontal $0.0444 \mathrm{~m}$ diameter, $1.02 \mathrm{~m}$ long test section from bottom through black/white vertical pipe on left; air enters through top of reservoir on right and exits test section through top of vertically-oriented pipe on left; a sight glass is shown at downstream end of test section on right.

The Air-Water Apparatus was used to provide complementary data to that of the Steam-Water Loop. The Lexan construction of the Air-Water Apparatus enabled viewing of the pipe/reservoir junction and thus clear viewing of wave bridging that was projected to occur at this location. In addition, because the Air-Water Apparatus was open to atmosphere (at the upstream end of the test section), it was easy for the authors to add colored light liquid to form the stationary wedge and also it was easy for the authors to locate and record the total length of the wedge based on the location of its leading edge and the depth of the wedge as a function of test section length. Neither of the above actions were possible in the Steam-Water Loop even though the Steam-Water Loop consisted of glass test sections since it: (a) is a closed system such that dyes could not be added to track the wedge location of the lighter fluid (saturated water), (b) the exact location of the saturated wedge leading edge could not be tracked because often the saturated-subcooled water interface could not be clearly observed and (c) the most downstream glass observation port was approximately $0.3 \mathrm{~m}$ upstream of the test sectionvessel junction.

Two types of data were recorded using the Air-Water Apparatus: (1) wave bridging experiments and (2) flow experiments with a stratified, quasi-stationary wedge of light fluid over heavier flowing water, at varying flow rates with and without air flowing at various flow rates.

Air-Water Apparatus Wave Bridging Experiments: The wave bridging experiments confirmed that wave bridging occurs at the pipe inlet for the conditions of interest. Visual data are shown in Figure 4 in the form of sequential photographs taken at a 1/30-second interval. The photographs show the test section just upstream of the reservoir. A ruler, observable in the photographs, enables the wave location to be observed (see time $=0 \mathrm{~s}$ ) as it forms and then documents its movement in the upstream direction as a function of time. It is interesting to note that the canola oil is clearly observable as a stationary wedge resting about the water. The canola oil/water interface is shown as a continuous curve (similar to a secant curve) that descends from the test section into the reservoir. Water flows from the left to the right at a mean velocity of $0.138 \mathrm{~m} / \mathrm{s}$ while air moves above the free surface at a mean velocity of $5.98 \mathrm{~m} / \mathrm{s}$. Resting on the water surface, and separating the water from the air, is a layer of canola oil. As the wave forms, only a small perturbation is observed on the canola oil/water interface, while the wave at the canola oil/air interface grows in size and progresses in the direction countercurrent to the water flow. By $0.37 \mathrm{~s}$ the wave has grown high enough that it has bridged the distance between the free surface and the upper inner pipe wall. These data give the following important information for the theory and models:

1. The wave bridging occurs in the region of the vena contracta as postulated.

2. The water-canola oil interface is a smooth, continuous curve that may be adequately modeled using straightforward analysis techniques, e.g., trapezoidal integration instead of more sophisticated integration techniques.

3. The wave growth on the water-canola oil interface is small and may be approximated using simple techniques when considering the net lift forces. 


\section{Wave Bridging Event \\ September 19, 2008 \\ Water-Canola Oil}

\section{Gas velocity $=5.98 \mathrm{~m} / \mathrm{s}$ Water velocity $=0.138 \mathrm{~m} / \mathrm{s}$}

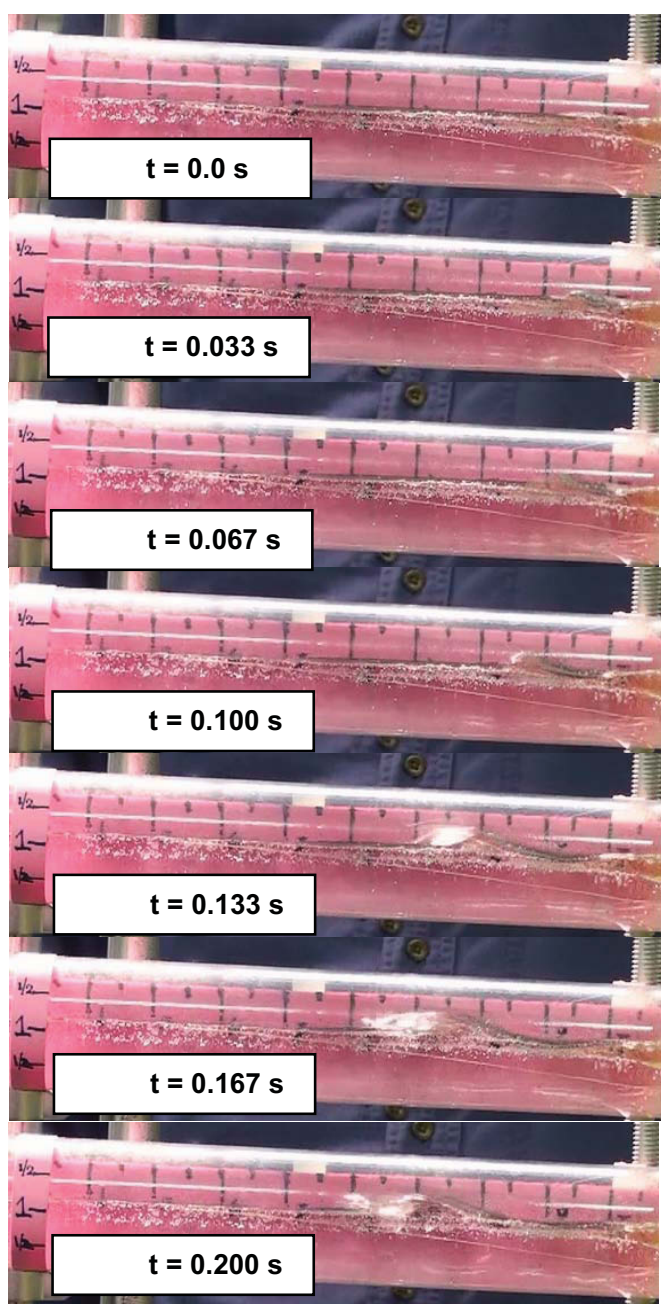

Picture sequence timing interval $=1 / 30 \mathrm{~s}$

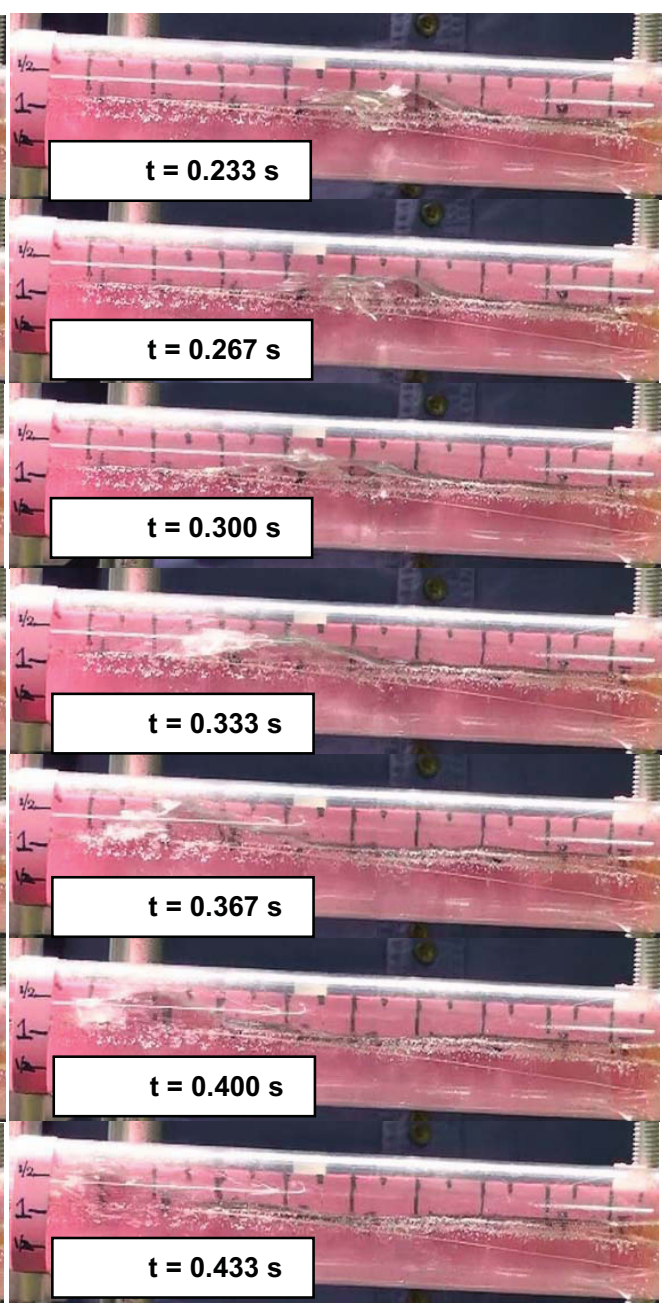

Figure 4. Timing sequence of a wave bridging event measured in the Air-Water Test Apparatus-scales measured in inches; water flows from left to right; air flows from right to left; wave bridging occurs at approximately $0.37 \mathrm{~s}$ after wave formation 
4. The wave growth of the lighter fluid resulting from increasing air velocities represents the most important wave bridging mechanism for which analytical modeling must account.

Data: Light Fluid Wedge Over Heavier Flowing Fluid: The bulk of the Air-Water Apparatus experiments focused on recording the location of a lighter fluid wedge over a heavier fluid as a function of water flow rates, depth, and air flow rate. Representative data are shown in Table 1 for water flow rate $(\mathrm{Q})$, thickness of lighter fluid $\left(\mathrm{h}_{1}\right)$, depth of heavier fluid $\left(\mathrm{h}_{2}\right)$, air velocity $\left(\mathrm{V}_{\text {gas }}\right)$, and wedge length $(\mathrm{m})$ measured from the wedge leading edge to the measurement station near the pipevessel juncture.

Table 1. Stratified Flow Data: Air-Water Apparatus

\begin{tabular}{|c|c|c|c|c|}
\hline $\mathrm{Q}\left(\mathrm{m}^{3} / \mathrm{s}\right)$ & $\mathrm{h}_{1}(\mathrm{~m})$ & $\mathrm{h}_{2}(\mathrm{~m})$ & $\mathrm{V}_{\text {gas }}(\mathrm{m} / \mathrm{s})$ & $\begin{array}{c}\text { Wedge } \\
\text { length }(\mathrm{m})\end{array}$ \\
\hline 0.0000158 & 0.0095 & 0.0126 & 0. & 0.812 \\
\hline 0.0000309 & 0.0079 & 0.0158 & 0. & 0.330 \\
\hline 0.0000334 & 0.0071 & 0.0174 & 0. & 0.203 \\
\hline 0.0000410 & 0.0040 & 0.0206 & 0. & 0.120 \\
\hline 0.0000442 & 0.0032 & 0.0214 & 0. & 0.064 \\
\hline 0.0000233 & 0.0040 & 0.0174 & 0. & 0.457 \\
\hline 0.0000158 & 0.0071 & 0.0158 & 0. & 0.800 \\
\hline 0.0000158 & 0.0079 & 0.015 & 0.36 & 0.901 \\
\hline 0.0000303 & 0.0048 & 0.0174 & 0.36 & 0.381 \\
\hline 0.0000303 & 0.0056 & 0.0174 & 0.59 & 0.483 \\
\hline 0.0000303 & 0.0032 & 0.0182 & 0.86 & 0.572 \\
\hline 0.0000303 & 0.0032 & 0.0190 & 1.04 & 0.641 \\
\hline
\end{tabular}

The data portrayed in Table 1 are plotted, together with three points from Liou et al 2005 in Figure 5. The data are plotted with the square of the densimetric Froude number on the abscissa and the wedge length divided by the liquid depth on the ordinate where the liquid depth is measured at the plane of the wedge leading edge. The densimetric Froude number $\left(F r_{D}\right)$ is defined as:

$$
F r_{D}=\frac{V_{2}}{\left[\frac{\left(\gamma_{2-\gamma_{1}}\right)}{\gamma_{2}} \frac{g A_{2}}{2 R \sin \alpha}\right]^{1 / 2}}
$$

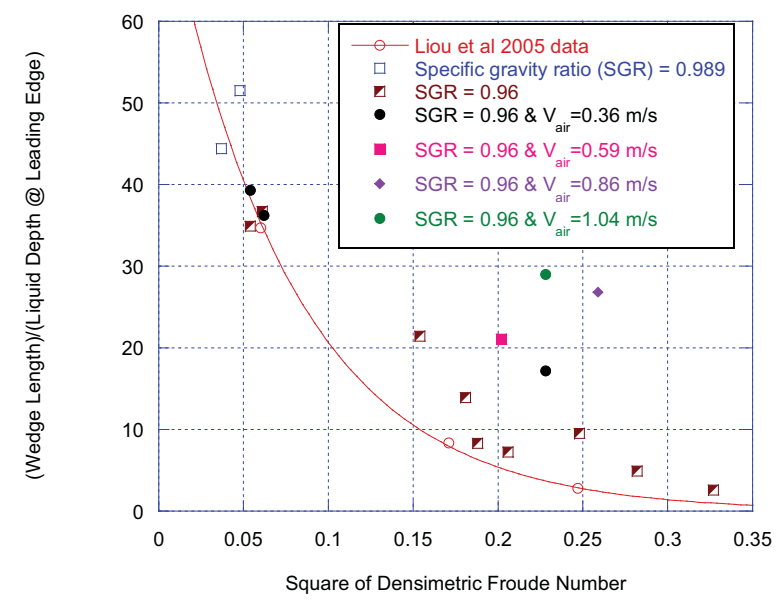

Figure 5. Variation of wedge length with densimetric Froude number

The data taken in the Air-Water Apparatus with no gas flow are shown in open symbols and closely agree with the Liou et al 2005 data at small densimetric Froude numbers, i.e., wedge lengths, but show larger magnitude wedge lengths for large densimetric Froude numbers. It should be noted that the exponential curve is drawn through the data of Liou et al 2005 for comparison to the data obtained in the Air-Water Apparatus. Considering the experimental uncertainties, the agreement is considered reasonable. The influence of countercurrent gas flow on the wedge location is shown by the solid data points. The wedge lengths for data with air flow show: (a) greater wedge lengths than data with no air flow at similar densimetric Froude numbers and (b) greater deviation with respect to data with no air flow as a function of increased velocity. The behavior shown in Figure 5 qualitatively agrees with the expected behavior. Analytical comparisons with these data are given in the next section.

Observations of interest from these data are:

1. The quasi-stationary wedge of stratified lighter liquid increases in length with the decreasing square of the densimetric Froude number in an exponential fashion as shown in Figure 5.

2. The data taken in the Air-Water Apparatus qualitatively agree with data recorded earlier by Liou et al 2005.

3. A wedge will only be present if the liquid flow is laminar.

4. The influence of gas flowing over the quasi-stationary wedge is to increase the wedge length with respect to 
data with no gas flow at equal densimetric Froude numbers.

5. The drag on the wedge increases with increasing gas velocity proportional to the gas velocity squared.

Steam-Water Loop: The Steam-Water Loop is capable of operations at $0.4 \mathrm{MPa}$ with steam produced by $65 \mathrm{~kW}$ powered electrical heater rods. In addition an auxiliary boiler is available for additional steaming capability if needed. The test section is comprised of $1.19 \mathrm{~m}$ long, $0.040 \mathrm{~m}$ diameter glass pipes plumbed to a steel receiver vessel that is vertically oriented and $0.78 \mathrm{~m}$ in diameter.

The Steam-Water Loop operates as a closed system where the water is recirculated using a loop centrifugal pump. The water flow is measured using a turbine meter. Steam flow measurements are taken at the inlet of the test section using a critical flow orifice and also at the end of the test section using another critical flow orifice such that the steam condensed in the test section can be roughly estimated within the experimental uncertainty. For the experiments described in this paper most of the data were taken at system pressures of approximately $0.1 \mathrm{MPa}$. Consequently, to measure the steaming rate at the upstream end of the test section, a steam catch tank was maintained, downstream of the system, at pressures of approximately $0.02 \mathrm{MPa}$ to ensure that the critical orifice at the upstream end of the test section was choked at all times. Temperatures of the steam and water were taken at regular intervals to monitor the system temperature behavior. The water level in the receiver was measured using a differential pressure transducer.

Demineralized water was used in the loop and the water subcooling was maintained between $50{ }^{\circ} \mathrm{C}$ and $70^{\circ} \mathrm{C}$. Griffith 1996 that ideal conditions for condensation-induced water hammer are: (i) subcooling greater than $20^{\circ} \mathrm{C}$, (ii) a horizontal pipe orientation, and (iii) pipe liquid fractions greater than 0.2. All of these conditions were designed into the Steam-Water Loop experimental hardware. The Steam-Water Loop is shown in Figure 6 and a close-up of the test section itself is shown in Figure 7.

The data recorded in the Steam-Water Loop complemented the Air-Water Apparatus data. Generally the experiments were performed by first achieving the desired saturated conditions at pressures slightly above atmospheric. The desired initial condition was achieved when a thick layer of saturated water was present in the reservoir covered by saturated steam. The initial reservoir water level was several centimeters above the top of the test section. Thereafter the loop flow was set at zero and the system water level was decreased by draining saturated water from the system through the test section using a valve located upstream of the test section. Using this approach saturated water was drawn into the test section such that as the

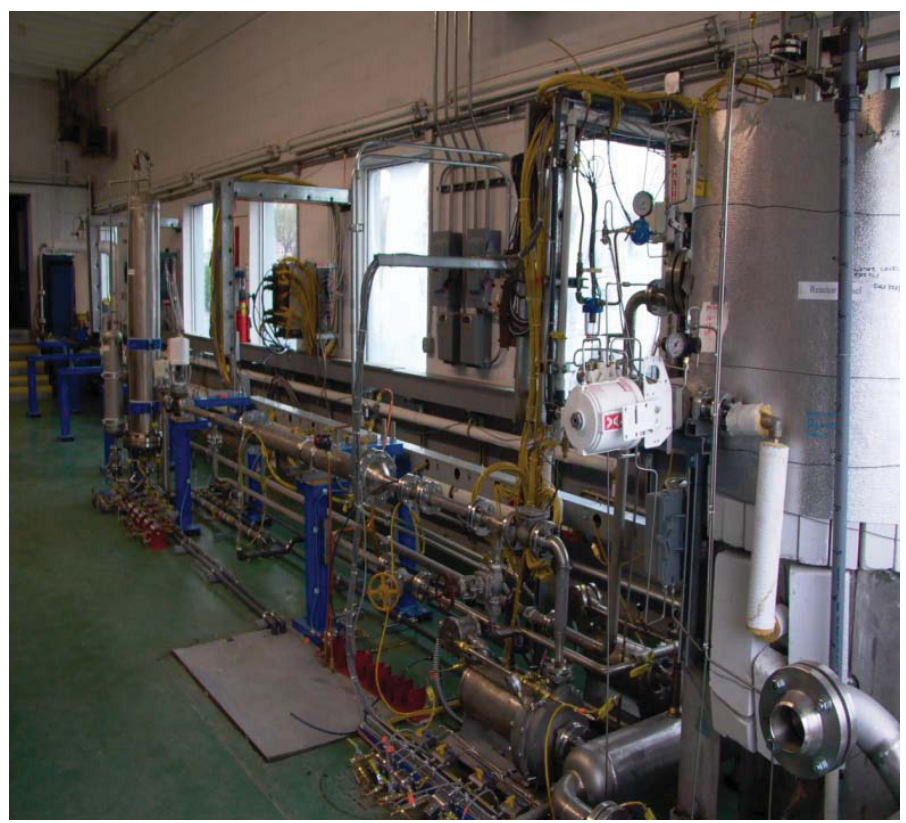

Figure 6. The Steam-Water Loop: the reservoir is at far right and the test section is immediately upstream of the reservoir. Loop piping is visible in the center of the photograph.

reservoir water level decreased only saturated water was present in the test section. The water level was decreased until the desired water level depth of the test section was achieved. Next the desired steam flow rate was set by opening valves between the auxiliary boiler and the bleed to the steam catch tank (a vacuum tank set at pressures less than $0.02 \mathrm{MPa}$ ). Upon achieving steady-state conditions, the flow of subcooled water into the test section was initiated.

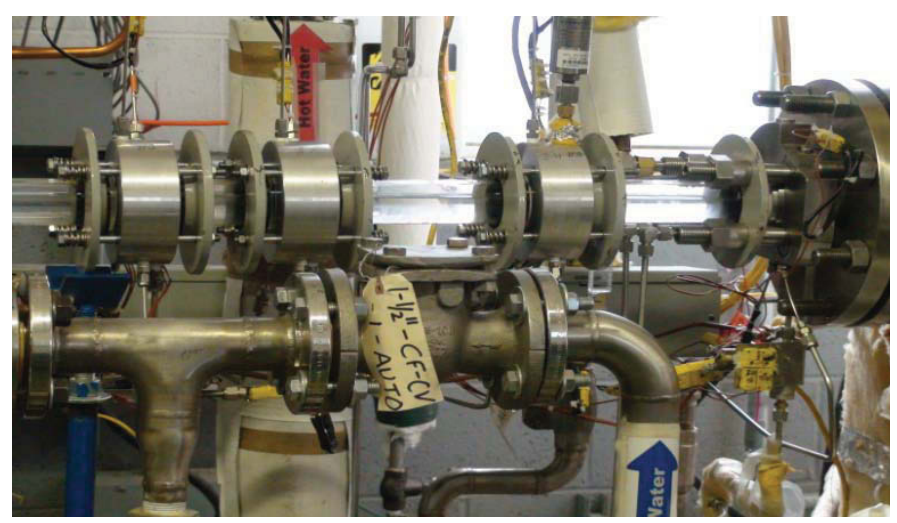

Figure 7. Portion of glass test section; glass sections are separated by instrumentation rings that house thermocouples; the flange on far right is inlet flange to reservoir-see Figure 6. 
The location of the leading edge of the wedge of saturated water was detected by visual observation. Although the exact location could not be determined with great accuracy, both the level of the subcooled water flow rate and the density-gradient induced distortion caused by the saturated-subcooled water interface were sufficient indicators to determine the approximate location of the wedge leading-edge. The wedge could be located to cover the entire length of the test section or the wedge could be driven toward the reservoir to expose some subcooled water to induce steam condensation. Unfortunately the thickness of the saturated water wedge could not be measured because the interface location could not be accurately determined and also the closest observation port to the junction of the test section pipe with the vessel was approximately $0.3 \mathrm{~m}$ upstream of the pipe-vessel junction.

Although accurate wedge geometry information could not obtained in the Steam-Water Loop, the loop was used to measure the following data types:

1. Whether a saturated wedge fully covered the entire length of the test section.

2. The test section void fraction.

3. The subcooled water flow rate and the steam flow rate; consequently, subcooled water velocities and steam velocities were obtained for a spectrum of conditions.

4. Condensation-induced water hammer (CIWH) events were planned and occurred at measured conditions.

A summary of the data taken in the Steam-Water Loop is listed in Table 2. The data include the water depth, the test section void fraction, the estimated subcooled water flow rate $\left(\mathrm{V}_{2}\right)$, the estimated steam velocity $\left(\mathrm{V}_{\mathrm{STM}}\right)$, and whether CIWH occurred. The steam velocity listed in Table 2 is based on the estimated test section void fraction, i.e., the full flow area available for the steam. However, as noted earlier, the steam velocity in the vicinity of the vena contracta was likely increased by area reductions that ranged from $60 \%$ to $80 \%$ of the steam flow area.

Table 2. Steam-Water Loop Data

\begin{tabular}{|c|c|c|c|c|}
\hline Depth $(\mathrm{m})$ & $\begin{array}{c}\text { Void } \\
\text { fraction }\end{array}$ & $\mathrm{V}_{2}(\mathrm{~m} / \mathrm{s})$ & $\begin{array}{c}\mathrm{V}_{\text {STM }} \\
(\mathrm{m} / \mathrm{s})\end{array}$ & $\begin{array}{c}\text { CIWH } \\
\text { occurred? }\end{array}$ \\
\hline 0.020 & 0.50 & 0.064 & 3.42 & No \\
\hline 0.023 & 0.41 & 0.037 & 4.17 & No \\
\hline 0.017 & 0.59 & 0.019 & 4.40 & No \\
\hline 0.018 & 0.55 & 0.043 & 3.12 & No \\
\hline 0.028 & 0.25 & 0.024 & 6.74 & Yes \\
\hline 0.027 & 0.27 & 0.042 & 6.36 & Yes \\
\hline 0.028 & 0.24 & 0.013 & 7.27 & Yes \\
\hline 0.028 & 0.25 & 0.020 & 6.77 & Yes \\
\hline
\end{tabular}

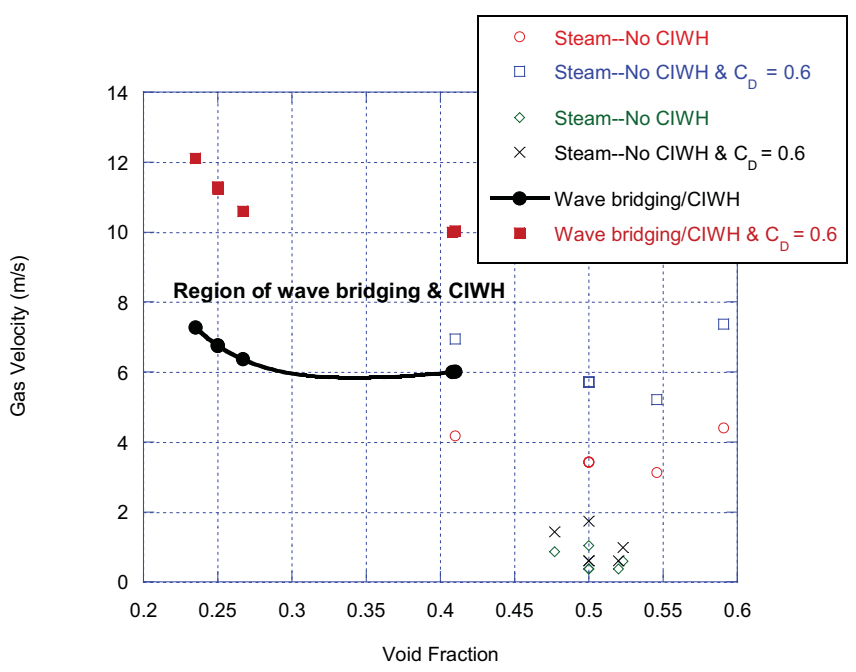

Figure 8. Steam-Water Loop data-test section void fraction vs steam velocities obtained with discharge coefficients of 0.6 and 1 at the pipevessel juncture. Note: data points@0.41 void fraction with gas velocities exceeding $6 \mathrm{~m} / \mathrm{s}$ were recorded in Air-Water Apparatus.

For all of the data listed above, the saturated wedge was estimated to fully cover the free surface for the length of the test section. The data given in Table 2 are shown in Figure 8 where the steam velocity data are shown with values representative of the steam using the available flow area and with a vena contracta present such that the steam flows through only $60 \%$ of the flow area.

In general the data show:

1. A saturated wedge can be maintained over the length of the test section length.

2. The saturated wedge prohibits CIWH from occurring unless the steam velocities are in the vicinity of $6 \mathrm{~m} / \mathrm{s}$.

3. Saturated wedges will only be maintained over the length of the test section under laminar flow conditions.

4. At steam velocities in excess of $6 \mathrm{~m} / \mathrm{s} \mathrm{CIWH}$ will occur even though a saturated wedge is present over the full length of the test section.

5. By visual observation it is noted that all CIWH events were initiated at the region where the test section joined the pressure vessel. These observations support the hypothesis that wave bridging and consequent CIWH will be initiated in this region for the systems of interest. 


\section{COMPARISON: THEORY AND DATA}

Using the data shown above, comparisons are given between the predicted behavior and the measured data for the location of the wedge, the influence of gas flowing over the wedge, and the initiation of wave bridging or CIWH.

Comparison of Calculated \& Measured Wedge Location: Using the equations developed in the section, "Location of the Saturated Liquid Layer," the predicted location of the leading edge of the wedge is compared with the measured location for the data with and without gas flow. The comparison is given in Figure 9.

The calculated wedge location, with no gas flow, tends to overestimate the measured wedge location - as shown in Figure 9 - although the calculated results give a reasonable prediction of the data. One potential explanation for the offset of the calculated predictions to the data may stem from the need to include the influence of the wall friction on the wedge location. That is, the numerical model developed in the first section of this paper does not include any accommodation for the friction of the pipe wall on the location of the wedge.

The calculated wedge location considering gas flow tends to underpredict the measured wedge location at low Froude numbers and to overpredict the wedge location at high Froude numbers. Because the argument presented in the previous paragraph also applies to these calculated values, it may be that the calculated wedge location considering the influence of gas flow requires more development to fully characterize the drag

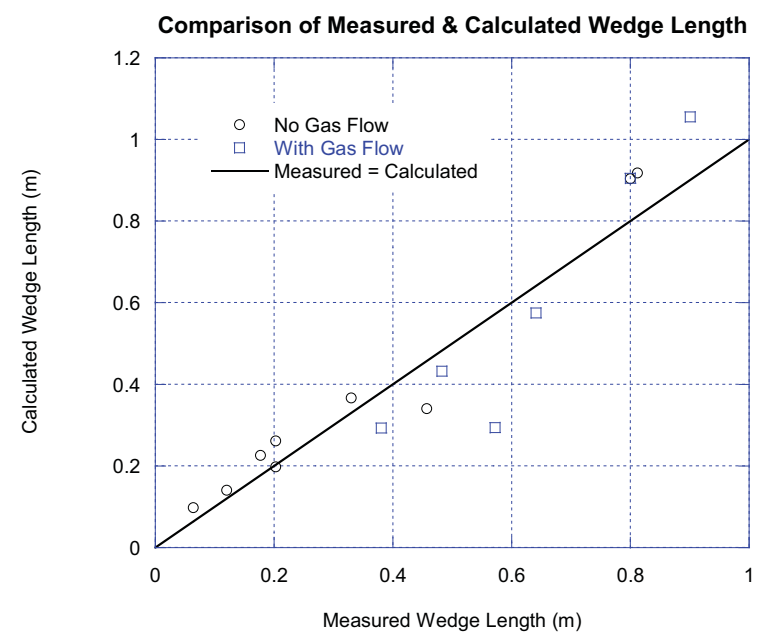

Figure 9. Comparison of calculated and measured wedge length exerted on the wedge by gas flow. However, considering that the model used was a simple, unaltered application of the work done by Blasius in 1908, the agreement between the data and the calculation is remarkably good. Certainly the model may be used to obtain a reasonable estimate of the wedge location considering the influence of gas flow.

Prediction of Wave Bridging and CIWH: The model developed in the section titled, "Influence of Gas Flow on Wedge," is based entirely on the vertical force balance exerted on the fluid element that encompasses the wave. Typical results are shown in Figure 10, where the numerical algorithm is used to identify a combination of forces, identified as the Bernoulli-effect stemming from the gas flow, the stagnation of the liquid flowing beneath the free surface, and the hydrostatic forces of the wave displacing gas that results in a positive derivative that increases for small increases in the wave height. For the case shown, considering an incoming gas velocity of 6 $\mathrm{m} / \mathrm{s}$, the three forces per unit area have the relative magnitudes of: $0.26 \mathrm{n} / \mathrm{m}^{2}, 10.99 \mathrm{n} / \mathrm{m}^{2}$ (for a relative increase in depth of 1 $\mathrm{mm}$ that corresponds to the $0.137 \mathrm{~m} / \mathrm{s}$ water flow rate), and $0.94 \mathrm{n} / \mathrm{m}^{2}$ respectively for a total lift force per unit area of 10.36 $\mathrm{n} / \mathrm{m}^{2}$. As the gas flow moves into the pipe and contracts, the lift force increases to a maximum of $10.5 \mathrm{n} / \mathrm{m}^{2}$ for a $1 \mathrm{~mm}$ wave height. Because the minimum area of the gas flow, located a small distance downstream from the pipe-vessel junction, is known only to be between a flow area fraction of 0.6 to 0.8 of the available flow area, the minimum flow area is uncertain and is a function of the chosen geometry configuration.

The lift force per unit area shown in Figure 10 gives the behavior of the combined forces described in the above paragraph for a gas flow stream that is $6 \mathrm{~m} / \mathrm{s}$ considering the available flow area of the steam space above the free surface together with the lift forces per unit area considering discharge coefficients of 0.86 and 0.75 at the plane of the minimum area in the vena contracta. Of these three traces, the calculation assuming a discharge coefficient shows an initial decrease in the lift with an increase in the wave height, reaches a minimum near zero, and then increases at a rate governed by a change in the gas velocity squared that results from the gas flow area being decreased by a growing wave. Because this trace represents the minimum force profile that always remains positive, it is indicative of the discharge coefficient representative of the vena contracta that leads to the rapid wave formation observed in this experiment. 


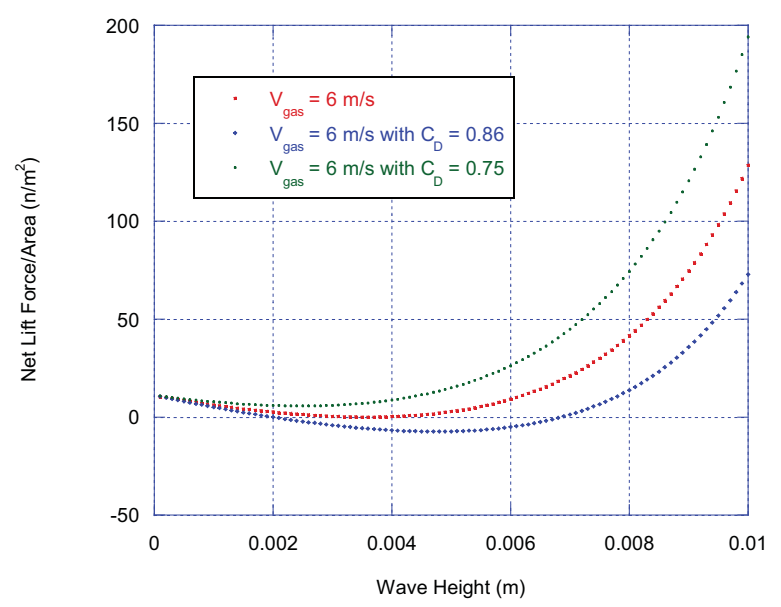

Figure 10. Net lift force/area as function of wave height for incoming gas velocities considering flow area contraction at location of vena contracta for Air-Water Test Apparatus Experiment 3.

\section{CONCLUSIONS AND OBSERVATIONS}

The experiments and analytical studies described above lead to the following conclusions and observations:

1. The physics that govern the formation and location of a quasi-static stratified wedge overlying heavier flowing liquid are understood and can be prescribed.

2. The conditions that lead to the formation and the maintenance of a quasi-static stratified wedge require laminar flow beneath the wedge.

3. When a quasi-static stratified wedge is maintained to separate saturated steam from highly subcooled water, wave bridging, and in particular condensation-induced water hammer, will be prevented.

4. For a horizontal pipe where steam is entering from a plenum in the countercurrent direction to flowing liquid flow, e.g., passively driven emergency core cooling system inventory, if the steam velocity is sufficiently large CIWH will occur. The CIWH event will occur in the vicinity of where the pipe is joined to the plenum.

5. Models have been developed that can be used to predict the location of a quasi-static wedge of lighter liquid above a heavier flowing liquid both in the static condition and considering gas flowing above the wedge. The models give reasonable agreement with the experimental data.

6. Models have been developed to calculate the gas flow rates that will lead to wave bridging and condensation- induced water hammer for the geometry described above - and give reasonable agreement with the experimental data.

\section{REFERENCES}

Bjorge, R. W., 1983, Initiation of Water Hammer in Horizontal or Nearly-Horzontal Pipes Containing Steam and Subcooled Water, MIT Doctoral Dissertation, January.

Bjorge, R. W. and P. Griffith, 1984, "Initiation of Waterhammer in Horizontal and Nearly Horizontal Pipes Containing Steam and Subcooled Water," Trans ASME, Journal of Heat Transfer, Vol. 106, November.

Blasius, 1908, "Grenzschichten in Flüssigkeiten mit kleiner Reibung," Z. Math. U. Phys, 56, 1; Engl. Translation in NACA Technical Memo No. 1256.

Bo Petersen, F., 1986, Environmental Hydraulic: Stratified Flows, Lecture Notes on Coastal and Estuarine Studies, No. 18, Springer-Verlag, Berlin.

Griffith, P., 1996, Screening Reactor Steam/Water Piping Systems for Water Hammer, NUREG-CR/6519, November.

Henderson, F. M., 1966, Open Channel Flow, Prentice-Hall Publishing, page 99.

Idel'chek, 1960, Handbook of Hydraulic Resistance, Israel Program for Scientific Translations, NTIS, p. 81.

Liou, C. P.; D. L. Parks; R. R. Schultz; and B. G. Williams, 2005, "Stratified Flows in Horizontal Piping of Passive Emergency Core Cooling Systems," ICONE13-50450, Proceedings of the International Conference on Nuclear Engineering-13, Beijing, China.

Minato, A.; T. Ikeda; and M. Naitoh, 1986, "Mechanistic Model of Slugging Onset in Horizontal Circular Tubes," Journal of Nuclear Science and Technology, No 23 (9), pp. 761-768, September.

Schlichting, H., 1960, Boundary Layer Theory, $4^{\text {th }}$ Edition, McGraw-Hill Book Co.

Schultz, R. R.; M. Kondo; and Y. Anoda, 2001, "Baseline Study to Model a Typical Condensation-Induced Water Hammer Event Measured at the Two-Phase Flow Test Facility (TPTF) in Japan," Proceedings of the Pressure Vessel and Piping Conference, Atlanta, July.

Schultz, R. R., 2010, Using Stratified Flow to Mitigate Condensation-Induced Water Hammer, Doctoral Dissertation, Idaho State University.

Taitel, Y. and A. E. Dukler, 1976, "A Model for Predicting Flow Regime Transitions in Horizontal and Near Horizontal Gas-Liquid Flow," pages 47 to 55, AIChE Journal, Vol. 22, No. 1, January.

Yonomoto, T.; M. Kondo; R. R. Schultz; and Y. Anoda, 1997, Quick Look Report of Experiment AP-DV-03, December.

Yonomoto, Y.; H. Nakamura; M. Suzuki; H. Asaka; M. Kondo; I. Ohtsu; Y. Shibamoto; Y. Kukita; R. R. Schultz; G. E. McCreery; J. M. Cozzuol; C. P. Liou; and G. Rhee; 2001, Summary Report of ROSA-AP600 Program, JAERI-memo 13009, March. 